\title{
Comparison of the Effects of Dibutyl and Monobutyl Phthalates on the Steroidogenesis of Rat Immature Leydig Cells
}

\author{
Linxi Li, ${ }^{1}$ Xiaomin Chen, ${ }^{2}$ Guoxin $\mathrm{Hu},{ }^{3}$ Sicong Wang, ${ }^{2}$ Renai Xu, ${ }^{2}$ Qiqi Zhu, \\ Xiaoheng Li, ${ }^{1}$ Mingcang Wang, ${ }^{4}$ Qing-Quan Lian, ${ }^{2}$ and Ren-Shan Ge ${ }^{1}$ \\ ${ }^{1}$ Center of Scientific Research, The Second Affiliated Hospital \& Yuying Children's Hospital, \\ Wenzhou Medical University, Wenzhou, Zhejiang 325027, China \\ ${ }^{2}$ Department of Anesthiology, The Second Affiliated Hospital \& Yuying Children's Hospital, \\ Wenzhou Medical University, Wenzhou, Zhejiang 325027, China \\ ${ }^{3}$ School of Pharmacy, Wenzhou Medical University, Wenzhou, Zhejiang 325035, China \\ ${ }^{4}$ Taizhou Hospital of Zhejiang Province, Taizhou 317000, China \\ Correspondence should be addressed to Mingcang Wang; wangmc@enzemed.com, \\ Qing-Quan Lian; lianqingquanmz@163.com, and Ren-Shan Ge; r_ge@yahoo.com
}

Received 3 January 2016; Accepted 17 February 2016

Academic Editor: Stelvio M. Bandiera

Copyright (C) 2016 Linxi Li et al. This is an open access article distributed under the Creative Commons Attribution License, which permits unrestricted use, distribution, and reproduction in any medium, provided the original work is properly cited.

\begin{abstract}
Dibutyl phthalate (DBP) is a widely used synthetic phthalic diester and monobutyl phthalate (MBP) is its main metabolite. DBP can be released into the environment and potentially disrupting mammalian male reproductive endocrine system. However, the potencies of $\mathrm{DBP}$ and MBP to inhibit Leydig cell steroidogenesis and their possible mechanisms are not clear. Immature Leydig cells isolated from rats were cultured with $0.05-50 \mu \mathrm{M}$ DBP or MBP for $3 \mathrm{~h}$ in combination with testosterone synthesis regulator or intermediate. The concentrations of $5 \alpha$-androstanediol and testosterone in the media were measured, and the mRNA levels of the androgen biosynthetic genes were detected by qPCR. The direct actions of DBP or MBP on CYP11A1, CYP17A1, SRD5A1, and AKR1C14 activities were measured. MBP inhibited androgen production by the immature Leydig cell at as low as $50 \mathrm{nM}$, while $50 \mu \mathrm{M}$ was required for DBP to suppress its androgen production. MBP mainly downregulated Cyplla1 and Hsd3b1 expression levels at $50 \mathrm{nM}$. However, $50 \mu \mathrm{M}$ DBP downregulated Star, Hsd3b1, and Hsd17b3 expression levels and directly inhibited CYP11A1 and CYP17Al activities. In conclusion, DBP is metabolized to more potent inhibitor MBP that downregulated the expression levels of some androgen biosynthetic enzymes.
\end{abstract}

\section{Introduction}

Dibutyl phthalate (DBP) is one of widely used synthetic phthalic diesters added to plastics to make them softer. It is used in the making of adhesives, dyes, lacquers, and personal care products. Since DBP is not bound to the final product, through its production and incorporation into products, DBP can be released into the environment. Therefore, DBP has become ubiquitous in the environment, resulting in human exposure $[1,2] . \mathrm{DBP}$ is a potential endocrine disruptor, especially acting on male reproductive system. A case-control study of 176 Chinese infertile men in Taiwan showed the inverse relationship of urine phthalate metabolite levels with Leydig cell function [3]. A cohort study with 501 males in USA also showed the inverse association of urine phthalate metabolites with semen quality [4]. Rodent models demonstrated that DBP can leach out from polyvinyl chloride plastics, disrupting androgen production [5]. DBP was reported to disrupt germ cell development [6], disturb testis development [7], block Leydig cell steroidogenesis [8, 9], and cause Leydig cell abnormal aggregation [10]. These studies indicate that DBP is an endocrine disruptor of male reproduction.

Structurally, DBP is a diester. It has been demonstrated that the diester forms of phthalates are rapidly hydrolyzed by esterases in the gut, liver, and blood and are present in the body in monoester forms, which are considered the bioactive toxicants. For example, the monoester form of 


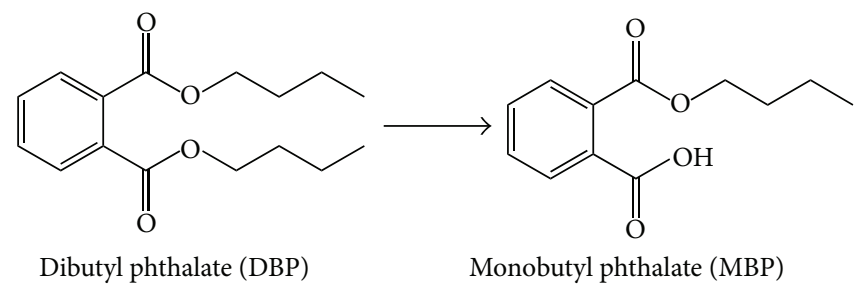

FIGURE 1: Structures of dibutyl phthalate and monobutyl phthalate and hydrolysis.

another phthalate called di(2-ethylhexyl) phthalate (DEHP), mono(2-ethylhexyl) phthalate (MEHP), is reported to be 10fold more potent in its toxicity to Leydig cells and Sertoli cells compared to DEHP [11]. In this regard, DBP is also metabolized into monobutyl phthalate (MBP) in the body and exists in the monophthalate form (Figure 1). However, the potencies of DBP and MBP to disrupt Leydig cell function as well as the possible mechanism have not been compared.

The puberty is the most sensitive period, during which Leydig cell development has been demonstrated to be disturbed by phthalates [11]. Leydig cells are the steroidogenic cells located in the interstitium of the testis and they produce mainly androgen, which is responsible for onset and maintenance of spermatogenesis and the second characteristics of males. During the puberty, stem Leydig cells exit quiescently, rapidly amplifying the cell number and differentiating into the Leydig cell lineage [12]. During development of Leydig cells in the rat, stem Leydig cells undergo transitions from immature Leydig cells around postnatal day 35 before these cells become mature $[13,14]$. The immature Leydig cell is a very unique cell that produces predominantly $5 \alpha$-androstane- $3 \alpha, 17 \beta$-diol (DIOL), because it contains both testosterone biosynthetic and metabolizing enzymes [14]. The testosterone biosynthesis starts substrate cholesterol. The testosterone biosynthetic enzymes include mitochondrial P450 cholesterol side chain cleavage enzyme (CYP11A1, encoded by Cyp11al) and smooth endoplasmic reticulum enzymes $3 \beta$-hydroxysteroid dehydrogenase 1 (HSD3B1, encoded by Hsd3b1), P450 17 $\alpha$-hydroxylase/20lyase (CYP17A1, encoded by Cyp17al), and $17 \beta$ hydroxysteroid dehydrogenase 3 (HSD17B3, encoded by Hsd17b3). Immature Leydig cells express high levels of smooth endoplasmic reticulum steroid $5 \alpha$-reductase 1 (SRD5Al, encoded by Srd5al) and cytosolic $3 \alpha$-hydroxysteroid dehydrogenase (AKR1C14, encoded by Akr1c14). The testosterone via biosynthesis in immature Leydig cells undergoes metabolism into dihydrotestosterone (DHT) by SRD5A1 and further into DIOL by AKR1C14 (Supplementary Figure 1 in Supplementary Material available online at http://dx.doi.org/10.1155/2016/1376526) [14].

The androgen production in Leydig cells require a regulatory signal, which is achieved by pituitary-secreted luteinizing hormone (LH). LH binds to its $\mathrm{LH}$ receptor (LHCGR, encoded by Lhcgr) on the surface of immature Leydig cells, causing the elevation of intracellular cAMP [15]. The LHCGR-cAMP signaling cascade causes the increased expression of scavenger receptor class B member 1 (SCARB1, encoded by Scarb1), which helps transporting extracellular cholesterol via low-density lipoprotein, and steroidogenic acute regulatory protein (StAR, encoded by Star), which transports cytosolic cholesterol into the inner membrane, where CYP11A1 is located. In the present study, we also investigated the effects of both DBP and MBP on the expression levels of these genes.

\section{Materials and Methods}

2.1. Chemicals and Animals. $\left[{ }^{3} \mathrm{H}\right]$ Pregnenolone, $\left[{ }^{3} \mathrm{H}\right]$ progesterone, $\left[{ }^{3} \mathrm{H}\right]$ androstenedione, $\left[{ }^{3} \mathrm{H}\right]$ testosterone, and $\left[{ }^{3} \mathrm{H}\right]$ dihydrotestosterone were purchased from DuPont-New England Nuclear (Boston, MA). Unlabeled pregnenolone, progesterone, 17 $\alpha$-hydroxyprogesterone, androstenedione, and testosterone were obtained from Steraloids (Newport, RI). Dibutyl phthalate and monobutyl phthalate were purchased from Sigma (St. Louis, MO). Male Sprague Dawley rats (30-day-old) were purchased from Shanghai Animal Center (Shanghai, China). All animal procedures were approved by the Institutional Animal Care and Use Committee of Wenzhou Medical University and were performed in accordance with the Guide for the Care and Use of Laboratory Animals.

2.2. Immature Leydig Cell Isolation. After adjustment for five days, eighteen 35-day-old male Sprague Dawley rats were sacrificed by asphyxiation with $\mathrm{CO}_{2}$. Testes were removed and Leydig cells were purified as described previously [14]. In brief, animals were sacrificed in $\mathrm{CO}_{2}$ tank, testes were removed, perfused with collagenase $(0.1 \mathrm{mg} / \mathrm{mL})$ via testicular artery, digested with collagenase $(0.25 \mathrm{mg} / \mathrm{mL})$ and DNase $(0.25 \mathrm{mg} / \mathrm{mL})$ for $15 \mathrm{~min}$, and filtered with nylon mesh, and the cells were separated under Percoll gradient. The cells with density of $1.070-1.088 \mathrm{~g} / \mathrm{mL}$ were collected and washed. Purities of Leydig cell fractions were evaluated by histochemical staining for HSD3B1 activity, with $0.4 \mathrm{mM}$ etiocholanolone as the steroid substrate [16]. The purities of Leydig cells were around 95\% consistently.

2.3. Leydig Cell Culture. After isolation, the purified immature Leydig cells were seeded into 24 -well culture plated with cell density of $0.05 \times 10^{6}$ cells/well. Leydig cells were cultured in 0.5 mL DMEM:F12 medium (phenol-free) without (basal) or with hormone and signaling substances, $10 \mathrm{ng} / \mathrm{mL} \mathrm{LH}$ 
and $10 \mathrm{mM}$ 8-bromo-cAMP (8Br-cAMP), $20 \mu \mathrm{M}$ of various steroid substrates including 22R-OH-cholesterol (22R$\mathrm{OHC}$ ), pregnenolone, progesterone, androstenedione, testosterone, and dihydrotestosterone for $3 \mathrm{~h}$ in the presence of $0.05-50 \mu \mathrm{M}$ DBP or MBP (DBP or MBP was dissolved in ethanol and ethanol was the control). Because $8 \mathrm{Br}$-cAMP can penetrate the cell membrane, therefore it is used to replace the intracellular cAMP, which is impermeable. 22R-OHC, pregnenolone, progesterone, androstenedione, testosterone, and dihydrotestosterone were used as the respective substrate of the enzymes CYP11A1, HSD3B1, CYP17A1, HSD17B3, SRD5A1, and AKR1C14. Because 22R-OHC can readily penetrate cell and mitochondrial membrane, it is used to replace cholesterol as substrate for CYP11A1. Media were collected for DIOL and testosterone assay after incubation.

\subsection{Preparation of Mitochondrial, Cytosol, and Microsomal} Proteins. Mitochondrial, cytosol, and microsomal preparations of rat testes were done as described previously [17]. Testes (from 35-day-old Sprague Dawley male rats) were homogenized in cold $0.01 \mathrm{mM}$ phosphate buffered saline (PBS) containing $0.25 \mathrm{mM}$ sucrose and centrifuged at $700 \times \mathrm{g}$ for $30 \mathrm{~min}$. The supernatants were transferred to new tubes and centrifuged at $10,000 \times \mathrm{g}$ for another $30 \mathrm{~min}$ and washed twice to collect mitochondrial pellet. Supernatants then were further centrifuged at $105,000 \times \mathrm{g}$ for $1 \mathrm{~h}$ twice to collect microsomal pellet and supernatant as cytosol. Pellets were resuspended and protein concentrations in these fractions were measured using the Bio-Rad Protein Assay Kit (cat\# 500-0006, Bio-Rad, Hercules, CA) according to manufacturer's protocol. Mitochondria were used for CYP11A1 measurement. Microsomes were used for measurement of CYP17A1 and SRD5A1 enzyme activities. Cytosol was used for AKR1C14 measurement.

2.5. CYP11A1 Assay. CYP11A1 activity in testicular mitochondria was assayed using $22 \mathrm{R}-\mathrm{OHC}$ as a substrate and pregnenolone as a product. Briefly, 22R-OHC $(20 \mu \mathrm{M})$ was dissolved in ethanol, with final ethanol concentration in the reaction solution no more than $0.2 \%$. In assays to determine the inhibitory potencies of DBP and MBP, concentrations of $22 \mathrm{R}-\mathrm{OHC}$ at $20 \mu \mathrm{M}$ were added to reaction mixture containing $10 \mu \mathrm{g}$ rat testis mitochondria and $50 \mu \mathrm{M}$ DBP and MBP, and the mixtures were incubated at $34^{\circ} \mathrm{C}$ for $3 \mathrm{~h}$. By end of incubation, the product, pregnenolone, was assayed by RIA kit. The percentage conversion of 22R-OHC into pregnenolone was calculated by pregnenolone from the substrate.

2.6. Enzymatic Assays of CYP17A1, SRD5A1, and AKR1C14. The testicular microsomal and cytosol enzymatic assays were done as described previously [18]. The detailed conditions for each enzymatic assay were listed as follows: briefly, the mixture $(250 \mu \mathrm{L})$ of the substrates $(0.2 \mu \mathrm{M}$ P4 for CYP17A1, $0.2 \mu \mathrm{M} \mathrm{T}$ for SRD5A1, and $1 \mu \mathrm{M}$ DHT for AKR1C14), the tracers $(40,000 \mathrm{dpm})$, and cofactors (NADPH, $0.2 \mathrm{mM}$, for all these enzymes) were incubated with certain amounts of enzymes (microsomal fractions for CYP17A1 and SRD5A1 or cytosol fraction for AKR1C14) for $60-90 \mathrm{~min}$ at $34^{\circ} \mathrm{C}$ (the temperature of normal testis). For some reactions, DBP and MBP were added as inhibitors (up to $50 \mu \mathrm{M}$ ). By the end of incubations, the reactions were stopped by adding $2 \mathrm{~mL}$ ice cold ether. The steroids were extracted, and the organic layer was dried under nitrogen. Steroids were separated chromatographically on thin layer plates (BakerFlex Silica Gel IB-F coated with $200 \mu \mathrm{m}$ analytical layer and fluorescent indicator, $20 \times 20 \mathrm{~cm}$, Thomas Scientific, Swedesboro, NJ) in chloroform-ether $(7: 1, \mathrm{v} / \mathrm{v})$ for CYP17A1 assay or chloroform-methanol $(97: 3, \mathrm{v} / \mathrm{v})$ for SRD5A1 or diethyl ether-acetone $(98: 2, \mathrm{v} / \mathrm{v})$ for the AKR1C14 assay. The radioactivity was measured using a scanning radiometer (System AR2000, Bioscan Inc., Washington, DC). The percentage conversion of the substrates into products was calculated by dividing the radioactive counts identified as products by the total counts of substrates plus products.

2.7. Assay of Pregnenolone, DIOL, and Testosterone Concentrations. Pregnenolone, DIOL, and testosterone concentrations in the medium were measured with a tritium-based radioimmunoassay as described [14], using the commercial RIA kits (IBL, USA). Interassay variation of the pregnenolone, DIOL, and testosterone was within $15 \%$.

2.8. Extraction of RNA and Real Time PCR (qPCR). Total RNAs were extracted from immature Leydig cells using Trizol reagent (Invitrogen, Carlsbad, CA, USA) according to the manufacturer's instruction. Twelve Leydig cell genes and their primers were used as described previously [19, 20]. These genes are membrane receptor genes including Lhcgr, cholesterol transporting genes including Scarb1 and Star, and steroidogenic enzyme genes, including CYP11A1 (Cyp11a1), HSD3B1 (Hsd3b1), CYP17A1 (Cyp17a1), HSD17B3 (Hsd17b3), SRD5A1 (Srd5a1), and AKR1C14 (Akrlc14), as well as steroidogenesis-regulatory transcription factor Nr5al. The cell proliferation genes, including Pcna and Ccnd1, were also included. The relative mRNA levels of targeted genes were normalized to Rps16 (internal control gene). The RNA was reversely transcribed into cDNA using random hexamers and MMLV reverse transcriptase by the kit (Promega, CA) according to the manufacturer's instruction. qPCR was carried out in a $25-\mu \mathrm{L}$ reaction volume with SYBR Green detection system (Bio-Rad Laboratories, Inc., Hercules, CA, USA). Reactions were run on a Bio-Rad qPCR system (BioRad Laboratories, Inc., Hercules, CA, USA) for up to 40 cycles and the melting curves were always checked afterward.

2.9. Statistics. Data were subjected to analysis by Student's $t$ test to identify significant differences whenever two groups (a single concentration of DBP or MBP versus control) were compared. Data were subjected to analysis by Kruskal-Wallis test followed by ad hoc Dunnett's multiple comparisons to identify significant differences between the tested group and the control whenever three or more groups (multiple concentrations of DBP or MBP versus control) were compared. All experiments were repeated 3-5 times, depending on 


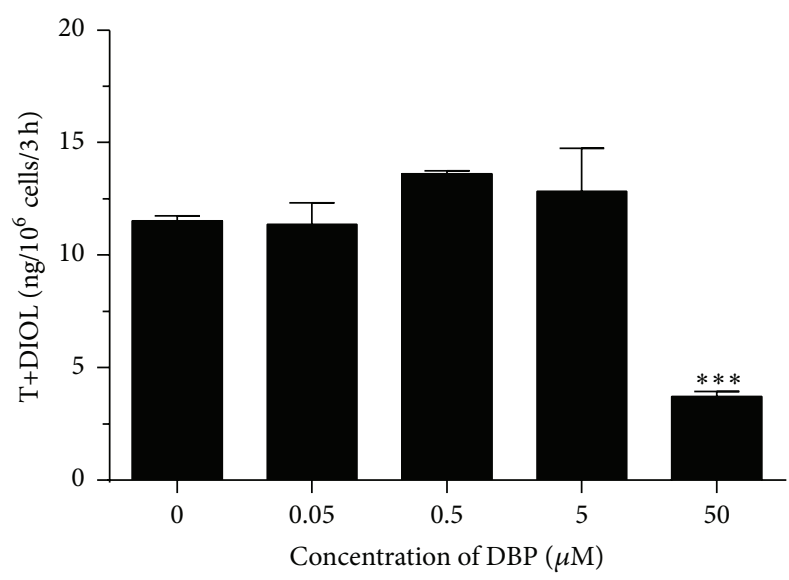

(a) $\mathrm{T}+\mathrm{DIOL}$

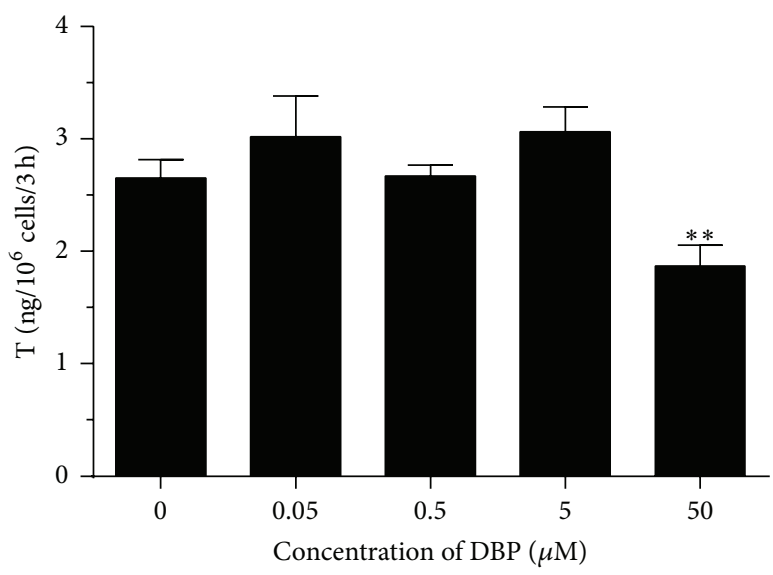

(c) $\mathrm{T}$

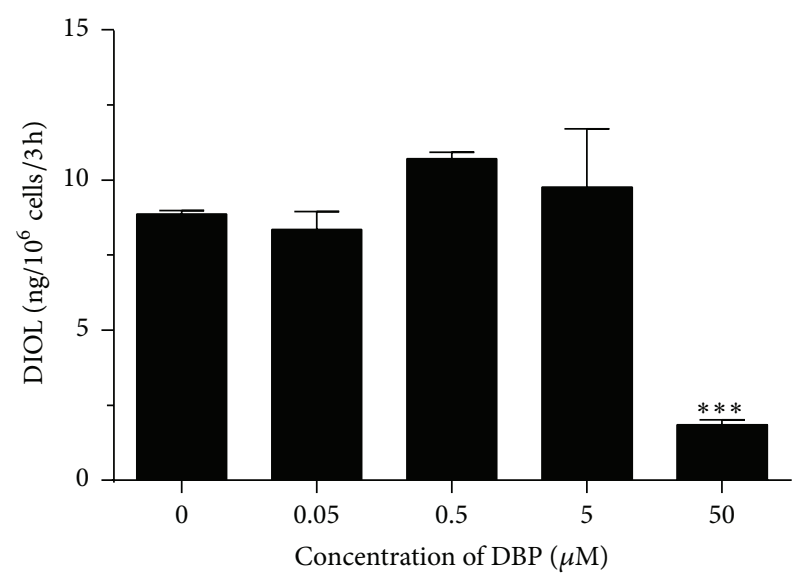

(b) DIOL

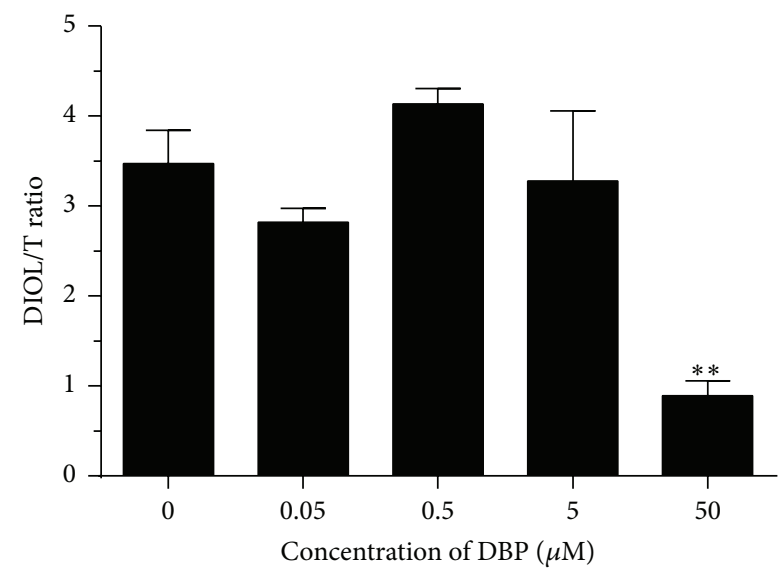

(d) $\mathrm{DIOL} / \mathrm{T}$

FIGURE 2: Concentration dependent effects of DBP on basal androgen production by rat immature Leydig cells. Rat immature Leydig cells were cultured with $0.05-50 \mu \mathrm{M}$ dibutyl phthalate (DBP) for $3 \mathrm{hrs}$. Medium testosterone (T) and $5 \alpha$-androstanediol (DIOL) levels were measured. (a) T + DIOL; (b) DIOL; (c) T; and (d) DIOL/T ratio. Mean \pm SEM, $n=4 ; *$, * , and $* * *$ indicate significant difference when compared to control at $P<0.05,0.01$, and 0.001 , respectively.

the experiments. All data are expressed as means \pm SEM. Differences were regarded as significant at $P<0.05$.

\section{Results}

3.1. Effects of DBP and MBP on Androgen Production in Rat Immature Leydig Cells. The rat immature Leydig cell primarily produces DIOL, because it contains androgen metabolizing enzymes (SRD5A1 and AKR1C14) [14] (Supplementary Figure 1). We tested the effects of DBP (Figure 2) and MBP (Figure 3) on androgen biosynthesis and metabolism. As shown in Figure 2, at the highest concentration $(50 \mu \mathrm{M})$ tested, DBP significantly inhibited total androgen (T + DIOL, Figure 2(a)), DIOL (Figure 2(b)), and T (Figure 2(c)) productions, indicating that DBP can inhibit androgen biosynthesis at this concentration. The ratio of DIOL to T (Figure 2(d)) was significantly reduced by $50 \mu \mathrm{M}$ DBP, indicating that androgen metabolism is also blocked at this concentration. MBP from the lowest concentration $(50 \mathrm{nM})$ to the highest concentration $(5 \mu \mathrm{M})$ inhibited total androgen (Figure 3(a)) and DIOL (Figure 3(b)) levels. Only at $50 \mu \mathrm{M}$ did MBP inhibit $\mathrm{T}$ production (Figure $3(\mathrm{c})$ ). The ratio of DIOL to $\mathrm{T}$ was not changed (Figure 3(d)), indicating that MBP does not influence androgen metabolism. This indicates that MBP is more potent than parent compound DBP to inhibit androgen production.

We further compared the effects of DBP and MBP on androgen production and metabolism of rat immature Leydig cells using $50 \mu \mathrm{M}$ concentration of each phthalate. We added hormone ( $\mathrm{LH}, 10 \mathrm{ng} / \mathrm{mL})$, signaling compound (8Br-cAMP, $10 \mathrm{mM}$ ), and steroidogenic enzyme substrates, including those of CYP11A1 (22R-OHC, $20 \mu \mathrm{M})$, HSD3B1 (pregnenolone, P5, $20 \mu \mathrm{M}$ ), CYP17A1 (progesterone, P4, $20 \mu \mathrm{M}$ ), HSD17B3 (androstenedione, D4, $20 \mu \mathrm{M}$ ), SRD5A1 (testosterone, T, $20 \mu \mathrm{M}$ ), and AKR1C14 (DHT, $20 \mu \mathrm{M}$ ), and measured the medium DIOL and $\mathrm{T}$ and then compared the total androgen $(\mathrm{T}+\mathrm{DIOL})$ with the control (no treatment, basal). As shown in Figure 4 (DBP), and as expected, under basal, LH, and 8Br-cAMP stimulations, DIOL was the major androgen, which accounted for 9-fold over T level (Table 1). At basal, LH, and 8Br-cAMP stimulated conditions, DBP 


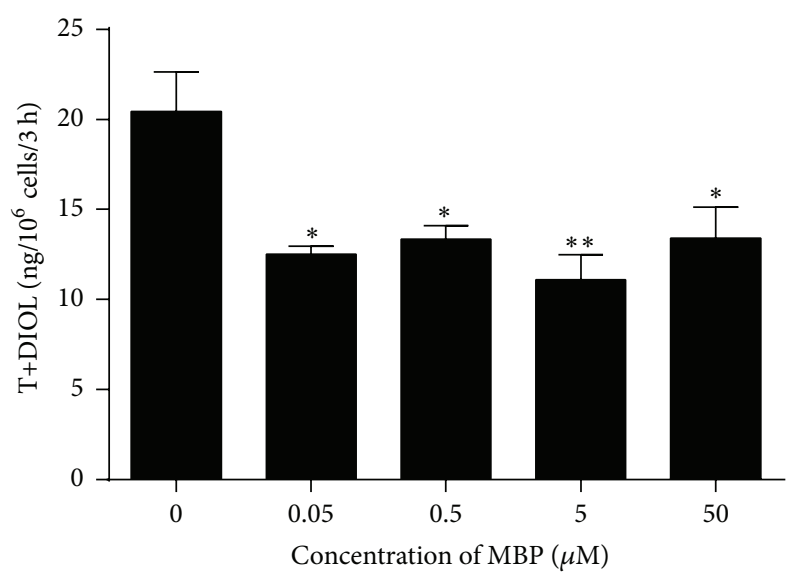

(a) $\mathrm{T}+\mathrm{DIOL}$

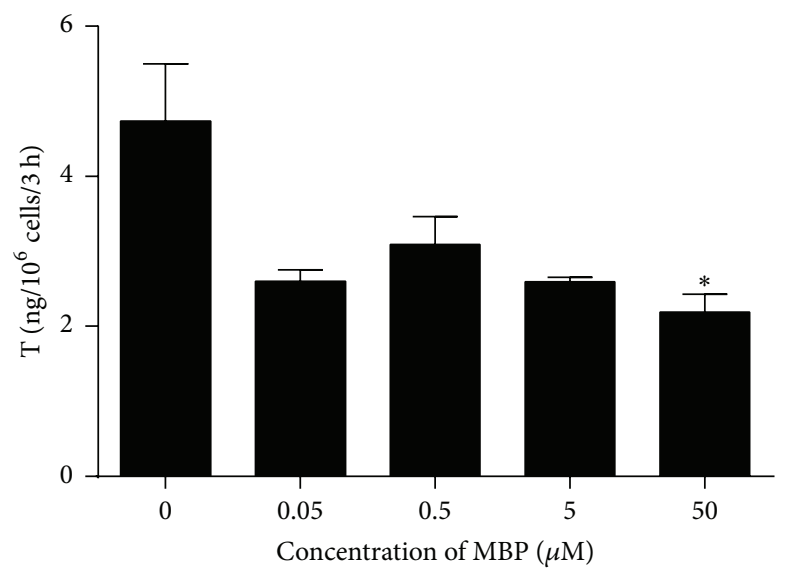

(c) $\mathrm{T}$

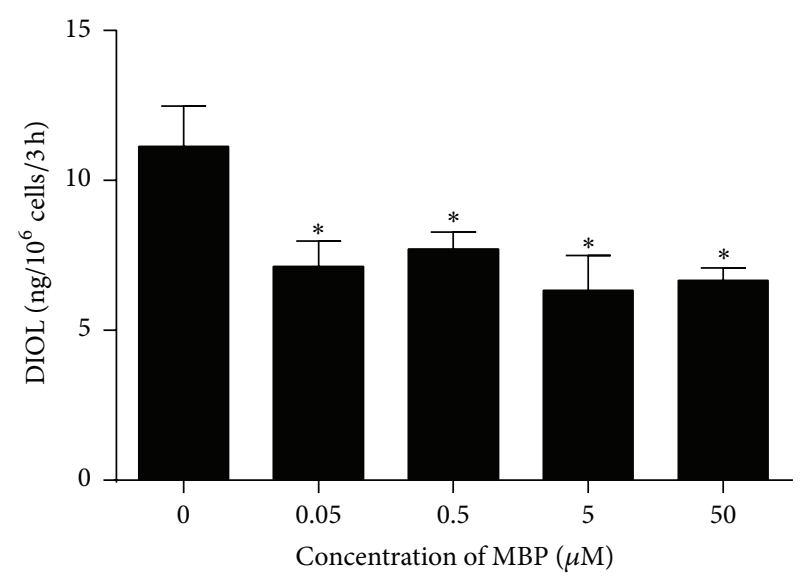

(b) DIOL

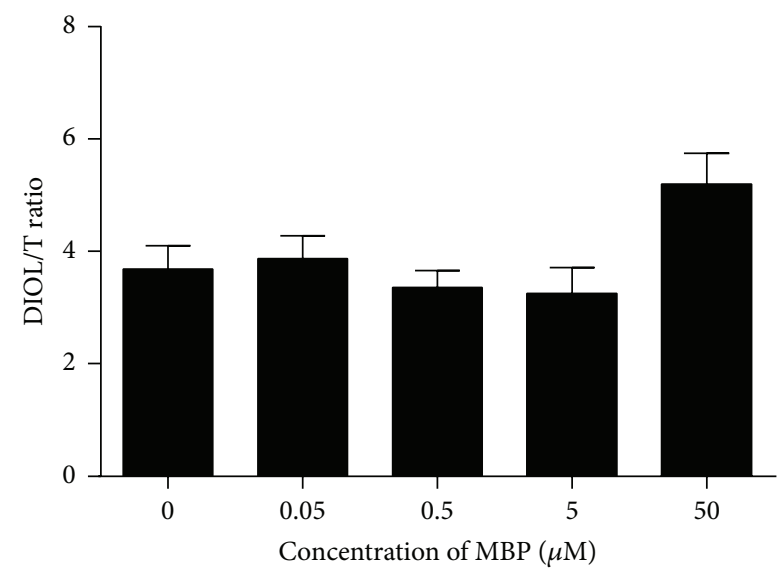

(d) $\mathrm{DIOL} / \mathrm{T}$

FIGURE 3: Concentration dependent effects of MBP on basal androgen production by rat immature Leydig cells. Rat immature Leydig cells were cultured with $0.05-50 \mu \mathrm{M}$ monophthalate (MBP) for $3 \mathrm{hrs}$. Medium testosterone (T) and $5 \alpha$-androstanediol (DIOL) levels were measured. (a) T + DIOL; (b) DIOL; (c) T; and (D) DIOL/T ratio. Mean \pm SEM, $n=4 ; *$, **, and $* * *$ indicate significant difference when compared to control at $P<0.05,0.01$, and 0.001 , respectively.

consistently inhibited $\mathrm{T}+$ DIOL productions. Because the inhibitions were comparable between $\mathrm{LH}$ and 8Br-cAMP stimulations, it is suggested that the inhibition site(s) may be beyond the LH signaling cascade. After addition of 22R$\mathrm{OHC}, \mathrm{P} 5, \mathrm{P} 4$, and $\mathrm{D} 4$ as substrates, the final androgen output ( $\mathrm{T}+\mathrm{DIOL}$ ) was all barely detectable for 22R-OHC, P5, and P4 but increased a little bit toward controls when D4 was used as a substrate (Figure $4(\mathrm{~g})$ ). It suggests that the major inhibition is between the cascades from cholesterol to androstenedione (CYP11A1, HSD3B1, and CYP17A1).

Interestingly, MBP did not inhibit LH- and 8BR-cAMP stimulated total androgen levels though it inhibited basal androgen level (Figure 5). After addition of 22R-OHC, P5, P4, and $\mathrm{D} 4$ as substrates, the final androgen outputs $(\mathrm{T}+\mathrm{DIOL})$ were not affected either by MBP, indicating that MBP does not affect CYP11A1, HSD3B1, CYP17A1, and HSD17B3 at this concentration.

When T and DIOL were considered separately (Table 1), the results were also intriguing. DBP caused remarkable reduction of DIOL levels at basal, LH, 8Br-cAMP, 22ROHC, P5, and P4 additions. With D4 as a substrate, T production was not affected (Table 1), while the production of DIOL was significantly reduced (Table 1). This suggests that, in addition to the $\mathrm{T}$ synthetic cascades, the $\mathrm{T}$ metabolizing cascades (SRD5A1 and AKR1C14) were also affected by DBP. Since there was a minimal reduction for DIOL, when $\mathrm{T}$ was used as the substrate, while there was a remarkable reduction when DHT was used as the substrate, it is possible that AKR1C14, not SRD5A1, is affected by DBP. For MBP, there were no dramatic effects for all conditions (Table 1), indicating that at this concentration MBP does not affect androgen biosynthetic and metabolizing enzymes.

3.2. Concentration Dependent Effects of DBP and MBP on the Expression Levels of Genes Related to Androgen Biosynthesis. We examined the effects of DBP on the expression levels of genes that are related to androgen biosynthesis and metabolism (Figure 5). Statistically, we found that at $50 \mu \mathrm{M}$ DBP significantly downregulated the Star, Hsd3b1, Hsd17b3, and Akrlc14 levels (Figure 5). The downregulation of Star level 


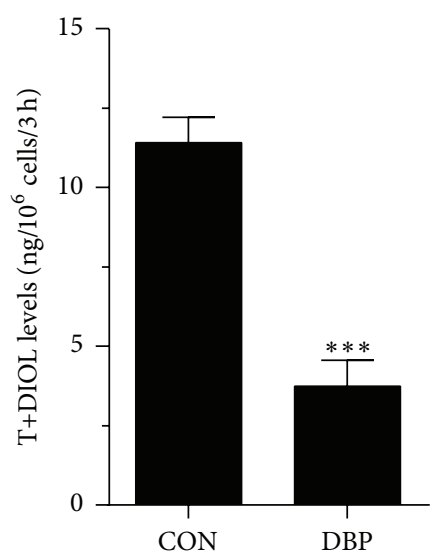

(a) Basal

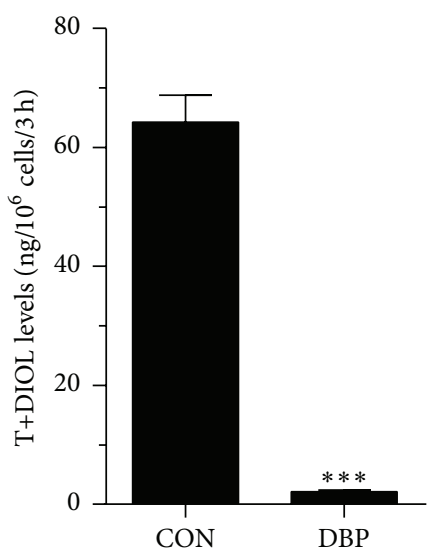

(d) 22R-OHC

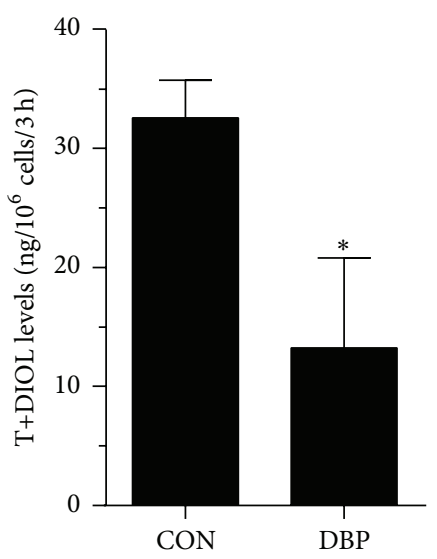

(b) $\mathrm{LH}$

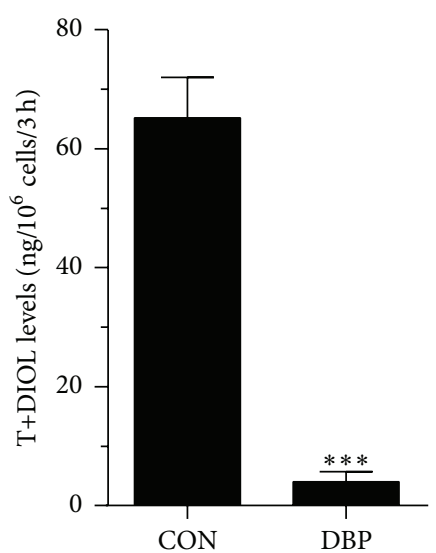

(e) P5

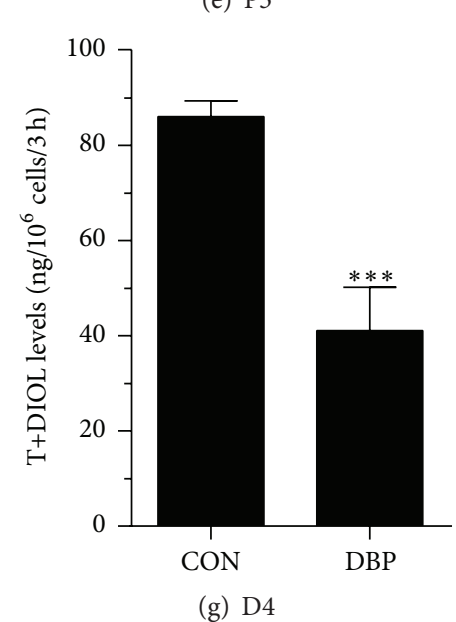

(g) D4

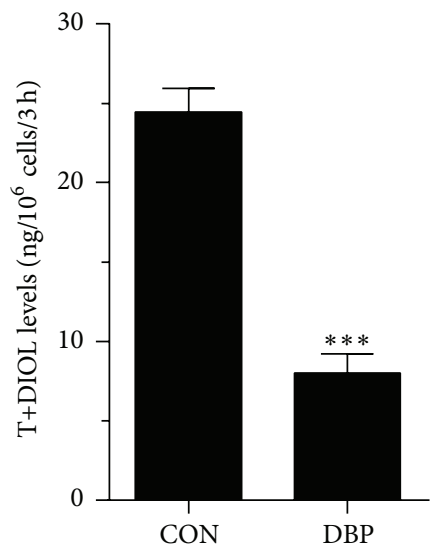

(c) 8 Br-cAMP

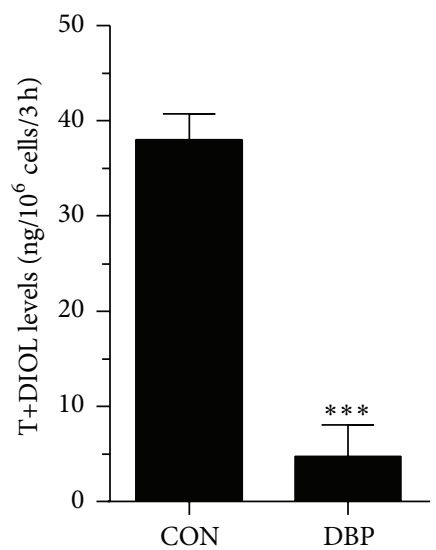

(f) $\mathrm{P} 4$

FIGURE 4: Effects of DBP on androgen production by rat immature Leydig cells. Rat immature Leydig cells were cultured without or with luteinizing hormone (LH), 8bromo-cAMP (8Br-cAMP), 22R-OH-cholesterol (22R-OHC), pregnenolone (P5), progesterone (P4), and androstenedione (D4) in combination with $50 \mu \mathrm{M}$ DBP for $3 \mathrm{hrs}$. Medium $5 \alpha$-androstanediol (DIOL) and testosterone (T) levels were measured. Mean $\pm \operatorname{SEM}, n=4 ; *, * *$, and $* * *$ indicate significant difference when compared to control at $P<0.05,0.01$, and 0.001 , respectively.

indicates that the rate-limiting step of cholesterol transportation from cytosol into inner membrane of mitochondrion is disrupted by DBP. The downregulation of $H s d 3 b 1, H s d 17 b 3$, and Akrlc14 levels also confirmed the inhibitions of DBP on their respective enzymes.
We also examined the effects of MBP on the expression levels of genes that are related to androgen biosynthesis and metabolism (Figure 6). Statistically, we found that at as low as 50 and $500 \mathrm{nM}$ MBP significantly downregulated the Cyp11a1 and Hsd3b1 levels (Figure 6) and at $5 \mu \mathrm{M}$ it inhibited 
TABLE 1: The effects of dibutyl phthalate (DBP) and monobutyl phthalate (MBP) on androgen production in rat immature Leydig cells.

\begin{tabular}{|c|c|c|c|c|c|c|}
\hline & \multicolumn{3}{|c|}{ Androstanediol (ng/10 6 cells $/ 3 \mathrm{~h})$} & \multicolumn{3}{|c|}{ Testosterone $\left(\mathrm{ng} / 10^{6}\right.$ cells $\left./ 3 \mathrm{~h}\right)$} \\
\hline & Control & DBP & MBP & Control & DBP & MBP \\
\hline Basal & $9.80 \pm 0.64^{\mathrm{a} *}$ & $1.91 \pm 0.19^{b}$ & $7.20 \pm 0.28^{c}$ & $3.68 \pm 0.47^{\mathrm{a} *}$ & $1.83 \pm 0.27^{\mathrm{b}}$ & $2.43 \pm 0.20^{\mathrm{b}}$ \\
\hline $\mathrm{LH}$ & $27.17 \pm 1.50^{\mathrm{a}}$ & $4.68 \pm 0.66^{\mathrm{b}}$ & $19.18 \pm 1.05^{\mathrm{c}}$ & $6.67 \pm 0.73^{\mathrm{a}}$ & $1.58 \pm 0.27^{\mathrm{b}}$ & $7.67 \pm 1.26^{\mathrm{a}}$ \\
\hline 8BR-cAMP & $19.47 \pm 0.59^{\mathrm{a}}$ & $6.46 \pm 0.44^{\mathrm{b}}$ & $11.27 \pm 0.21^{\mathrm{c}}$ & $4.99 \pm 0.85^{\mathrm{a}}$ & $1.56 \pm 0.18^{\mathrm{b}}$ & $5.29 \pm 0.62^{\mathrm{a}}$ \\
\hline 22R-OH-cholesterol & $51.43 \pm 2.63^{\mathrm{a}}$ & $2.06 \pm 0.11^{\mathrm{b}}$ & $41.14 \pm 0.89^{c}$ & $12.02 \pm 0.84^{\mathrm{a}}$ & $0.06 \pm 0.01^{\mathrm{b}}$ & $8.62 \pm 0.014^{\mathrm{a}}$ \\
\hline Pregnenolone & $48.26 \pm 2.55^{\mathrm{a}}$ & $3.51 \pm 0.85^{\mathrm{b}}$ & $42.39 \pm 5.29^{\mathrm{a}}$ & $16.85 \pm 1.32^{\mathrm{a}}$ & $0.55 \pm 0.09^{\mathrm{b}}$ & $16.70 \pm 1.27^{\mathrm{a}}$ \\
\hline Progesterone & $23.71 \pm 1.38^{\mathrm{a}}$ & $4.04 \pm 1.26^{\mathrm{b}}$ & $27.07 \pm 2.96^{\mathrm{a}}$ & $14.31 \pm 0.30^{\mathrm{a}}$ & $2.60 \pm 1.89^{\mathrm{b}}$ & $17.92 \pm 1.37^{\mathrm{a}}$ \\
\hline Androstenedione & $71.50 \pm 1.39^{\mathrm{a}}$ & $30.13 \pm 4.06^{\mathrm{b}}$ & $74.01 \pm 0.39^{\mathrm{a}}$ & $14.50 \pm 0.37^{\mathrm{a}}$ & $11.92 \pm 1.18^{\mathrm{a}}$ & $19.10 \pm 1.25^{\mathrm{b}}$ \\
\hline Testosterone & $92.37 \pm 0.58^{\mathrm{a}}$ & $82.90 \pm 2.17^{\mathrm{b}}$ & $85.56 \pm 1.34^{\mathrm{b}}$ & ND & ND & ND \\
\hline Dihydrotestosterone & $184.8 \pm 1.15^{\mathrm{a}}$ & $91.19 \pm 2.37^{\mathrm{b}}$ & $182.4 \pm 1.34^{\mathrm{a}}$ & ND & ND & ND \\
\hline
\end{tabular}

Mean \pm SEM, $n=4 \sim 12 . \mathrm{ND}=$ not detected. ${ }^{*}$ Identical letters indicate that there are no significant differences between two groups for either androstanediol or testosterone production.

Scarb1 level. Surprisingly, at $50 \mu \mathrm{M}$ none of the genes tested were affected. Interestingly, the level of transcription factor Nr5a1, which is critical for the regulation of expressions of Cyp11a1 and Hsd3b1, was significantly reduced by $50 \mathrm{nM}-$ $5 \mu \mathrm{M} \mathrm{MBP}$, corresponding to the downregulation of its target genes (Cyp11al and Hsd3b1).

3.3. The Direct Inhibition on Androgen Biosynthetic and Metabolizing Enzyme Activities by DBP and MBP. There was discrepancy between DBP-mediated effects on some steroidogenic enzyme expression levels and androgen production. At $50 \mu \mathrm{M}$ DBP did not affect Cyp11a1 and Cyp17a1 levels but caused almost barely detectable 22R-OHC and P4mediated androgen levels. We previously demonstrated that DBP directly inhibited rat HSD3B1 activity and marginally inhibited rat HSD17B3 activity, while MBP did not inhibit these enzymes at all [21]. We tested whether DBP and MBP also directly inhibited other androgen biosynthetic (CYP11A1, CYP17A1) and metabolizing enzyme (SRD5A1 and AKR1C14) activities. As shown in Figure 7, at $50 \mu \mathrm{M}$ DBP significantly inhibited CYP11A1, CYP17A1, and AKR1C14 activities, while it had no effect on SRD5A1 activity. MBP, at $50 \mu \mathrm{M}$, had no effects on all these enzyme activities. This indicates that the reduction of 22R-OHC and P4-mediated androgen production in DBP-treated cells is caused by its direct inhibition on these enzyme activities.

\section{Discussion}

In this study, the purified immature Leydig cell has shown different sensitivity to endocrine disruptor DBP and its metabolite MBP. In the in vitro culture environment, only high concentration $(50 \mu \mathrm{M})$ of DBP showed significant inhibition on the production of both testosterone (T) and DIOL. On the other hand, from low concentration (50 nM) to high concentration (5000 nM), MBP showed significant inhibition on androgen production.

When DBP enters the mammalian body, it is rapidly hydrolyzed by esterases in the gut, liver, and blood into MBP. It seems that DBP and MBP showed different potencies and mechanism to suppress steroidogenesis. Generally speaking, the metabolite MBP was more potent to inhibit androgen production (Figure 3). At as low as $50 \mathrm{nM}$, MBP significantly inhibited androgen production (Figure 3 ). This inhibition is mostly contributed by the downregulation of some steroidogenesis related genes, Cyplla1 and Hsd3b1. However, MBP did not block completely the transcription of these genes. The residual expression levels of these two genes were about $60 \%$. Thus, the residual activities of CYP11A1 and HSD3B1 were about $60 \%$ after 50-5000 nM MBP treatment (Figure 3). However, MBP did not directly inhibit androgen biosynthetic and metabolizing enzyme activities when up to $50 \mu \mathrm{M}$ was used. Therefore, the MBP-induced inhibition is most likely from its suppression of these gene expressions. Cyp11al and $H s d 3 b 1$ are the target genes of transcription factor NR5A1 (encoded by Nr5a1). The expression levels of Cyp11a1 and $H s d 3 b 1$ also followed the pattern of Nr5al after MBP treatment (Figure 6(j)). Interestingly, $50 \mu \mathrm{M}$ MBP did not interfere with steroidogenesis related gene expressions, indicating that higher concentration of MBP loses its action. We did not test even higher concentrations of MBP. However, our and other studies with another monophthalate, MEHP, also showed an even stimulatory action when higher concentrations were used.

Interestingly, the potency of DBP to inhibit androgen production was less than that of MBP. However, at $50 \mu \mathrm{M}$, DBP can cause significant inhibition of androgen production. This indicates that DBP was 1000-fold less potent than MBP. However, at $50 \mu \mathrm{M}$, DBP caused more deep inhibition of androgen production. The residual levels of androgen after DBP treatment at basal, LH, 8Br-cAMP, 22R-OHC, P5, $\mathrm{P} 4$, and D4 were $33 \%, 41 \%, 31 \%, 3 \%, 3 \%, 7 \%$, and $37 \%$, respectively. This level was achieved by DBP-mediated multiple mechanisms, especially via direction inhibition. In this regard, $50 \mu \mathrm{M}$ DBP induced 3.3\% residual levels of CYP11A1 (Figure 7). In our previous study, we also demonstrated that $50 \mu \mathrm{M}$ DBP also caused about $25 \%$ of residual activities of rat HSD3B1 and HSD17B3 [21]. Furthermore, $50 \mu \mathrm{M}$ DBP also decreased the expression levels of $H s d 3 b 1$ and $H s d 17 b 3$ by $45 \%$ and $34 \%$, respectively (Figure 5 ). Therefore, at this concentration, DBP caused more deep suppression of androgen production. 


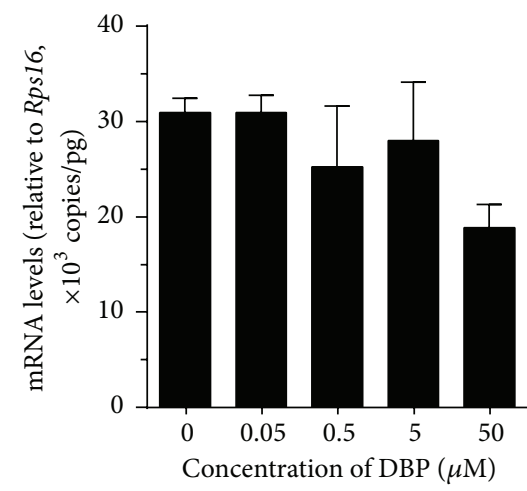

(a) Lhcgr

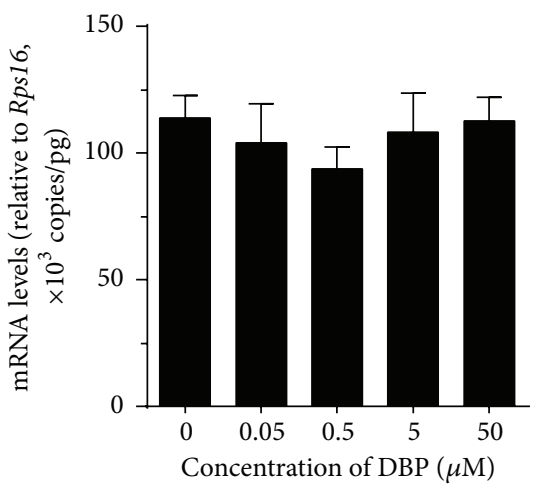

(d) Cypllal

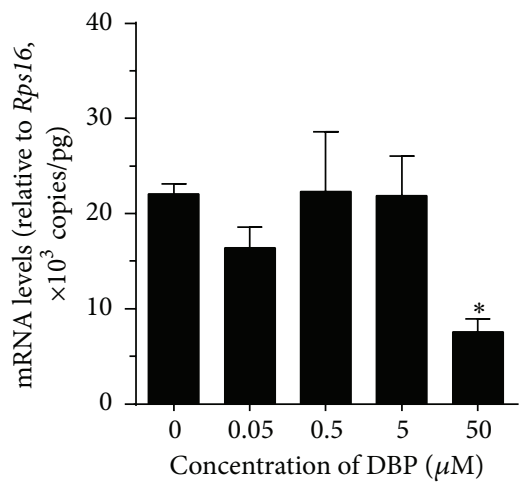

(g) Hsd17b3

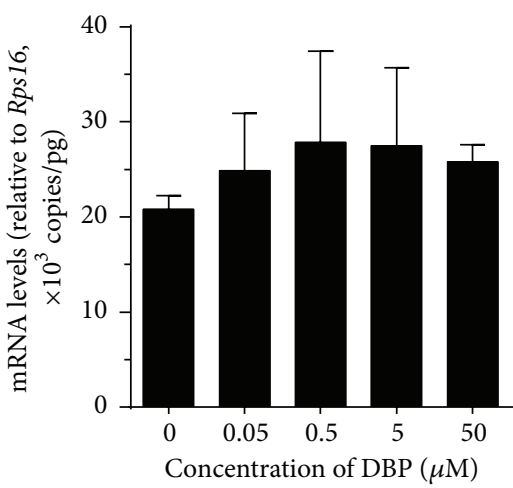

(j) Nr5al

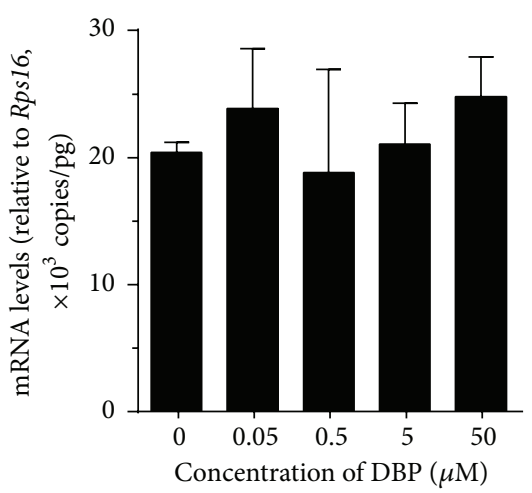

(b) Scarb1

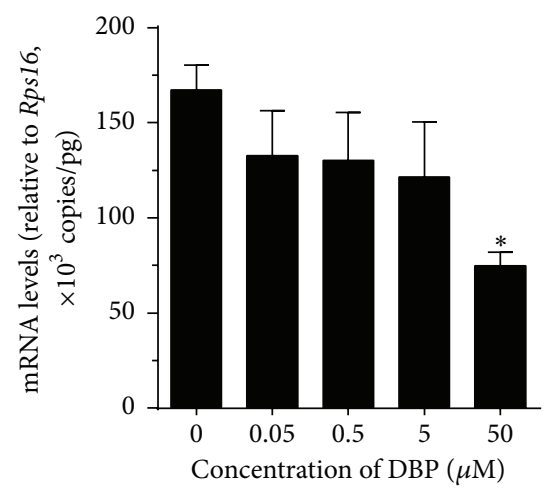

(e) Hsd3b1

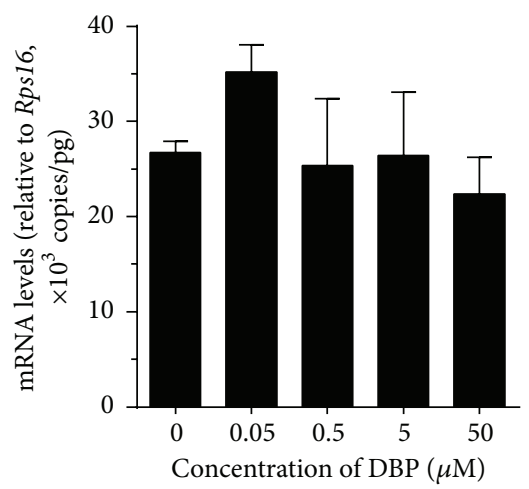

(h) Srd5al

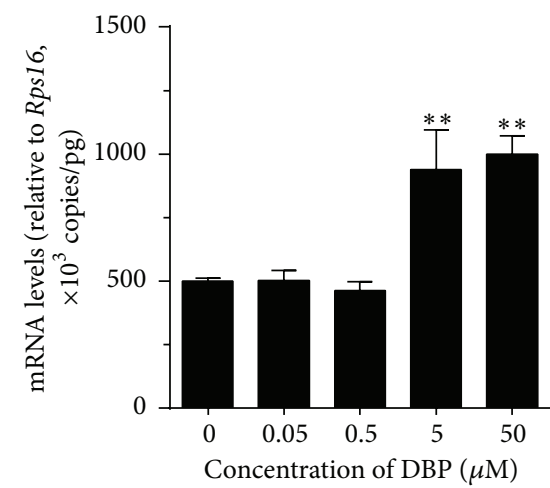

(k) Pcna

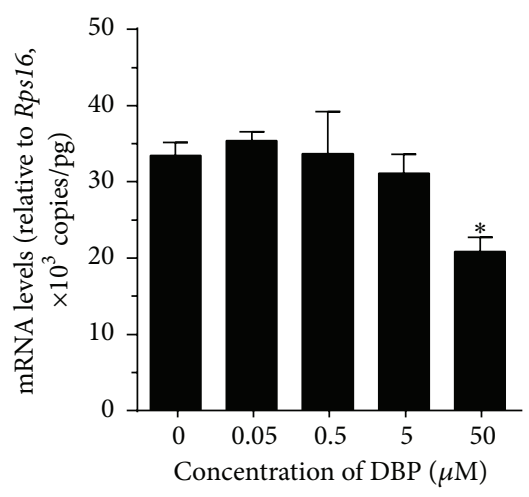

(c) Star

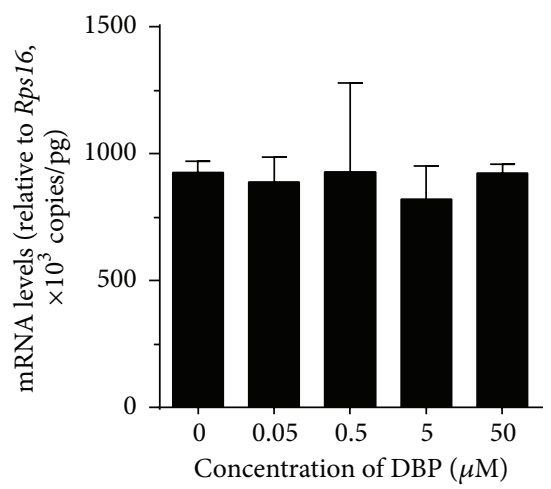

(f) Cyp17al

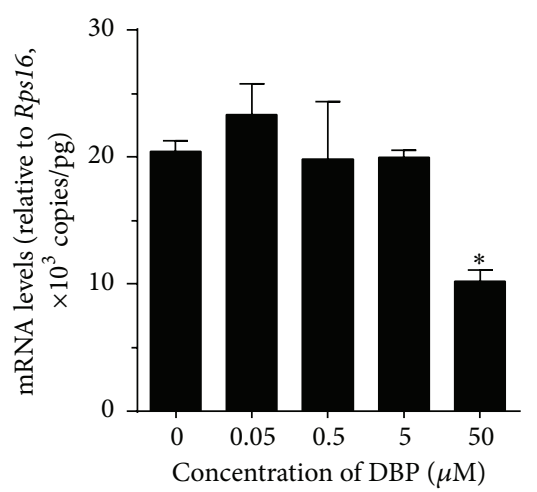

(i) AKR1C14

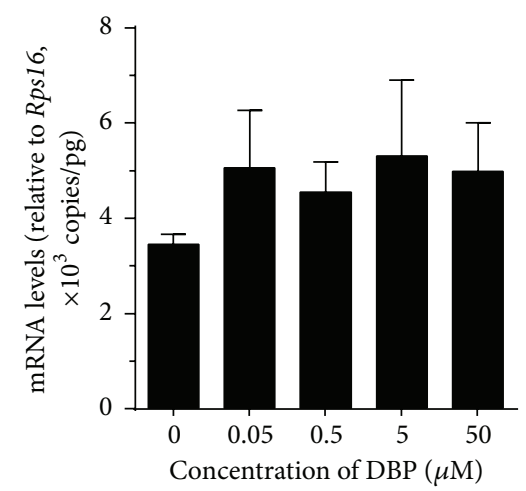

(l) Condl

FIGURE 5: Effects of DBP on the expression levels of steroidogenesis related genes in rat immature Leydig cells. Rat immature Leydig cells were cultured with $0.05-50 \mu \mathrm{M} \mathrm{DBP}$ for $3 \mathrm{hrs}$. The expression levels of steroidogenesis related genes were measured and calculated relatively to Rps16, the internal control. Mean $\pm \operatorname{SEM}, n=4 ; *, * *$, and $* * *$ indicate significant difference when compared to control at $P<0.05$, 0.01 , and 0.001 , respectively. 


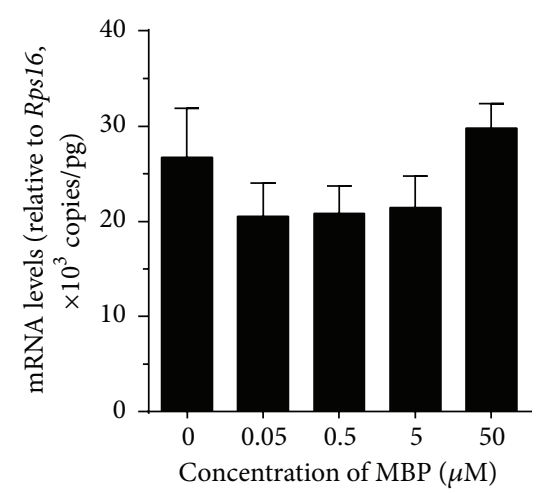

(a) Lhcgr

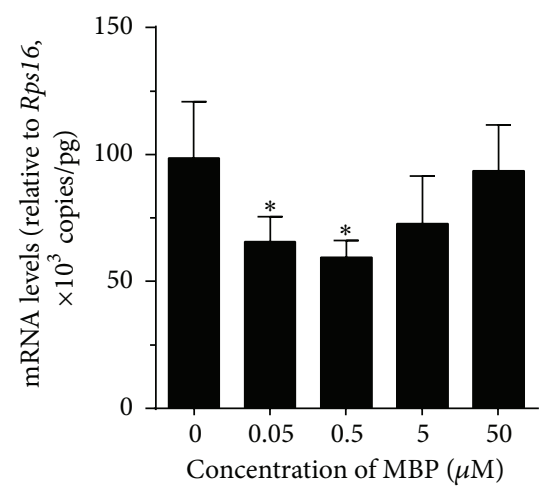

(d) Cyplla1

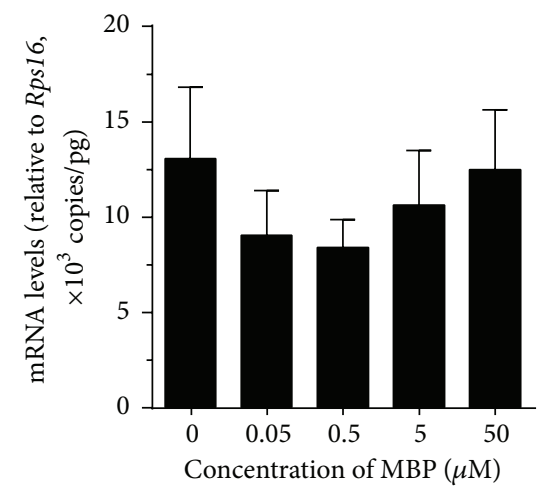

(g) Hsd17b3

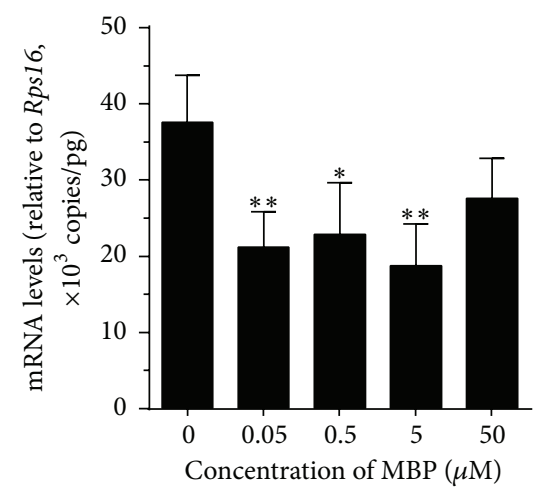

(j) Nr5al

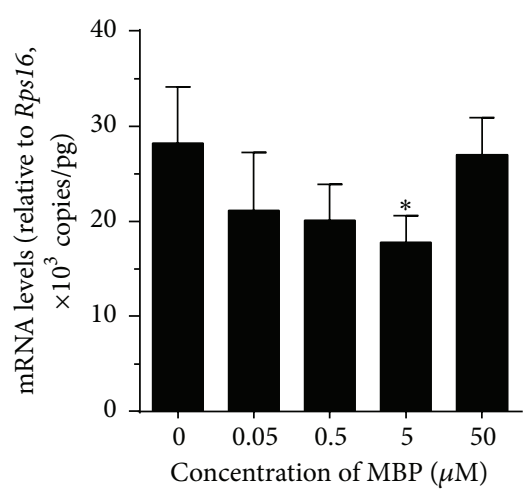

(b) Scarb1

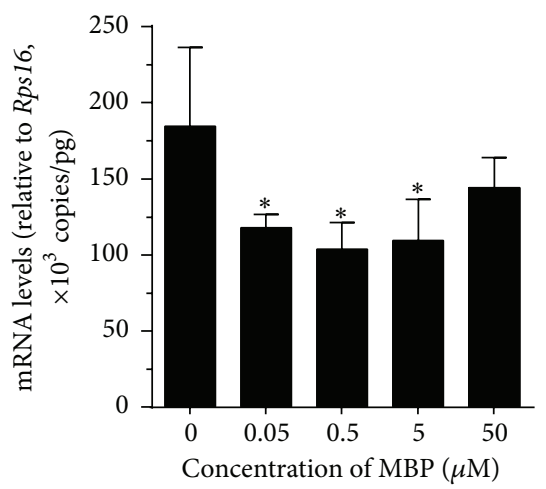

(e) Hsd3bl

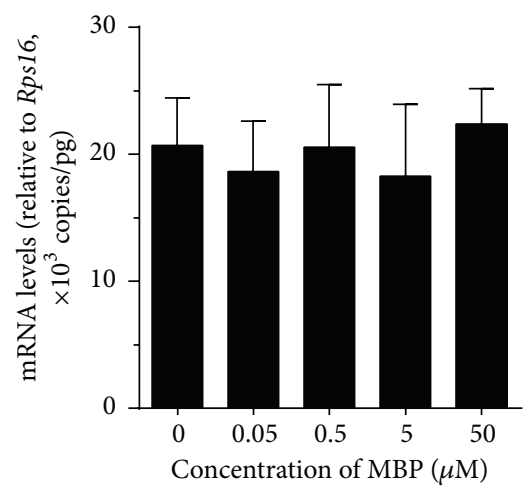

(h) Srd5al

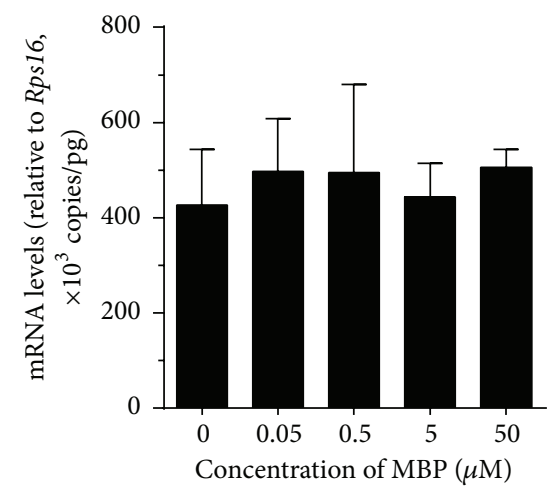

(k) Pcna

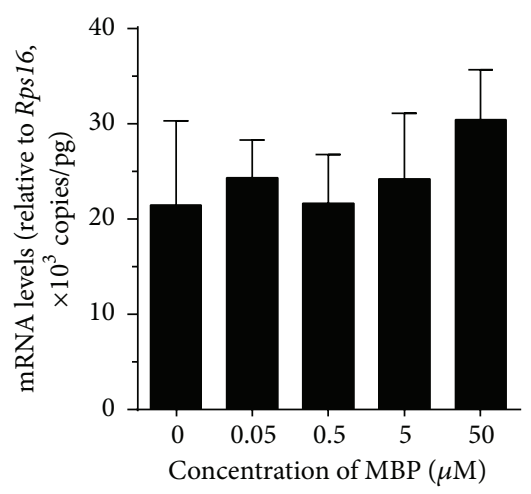

(c) Star

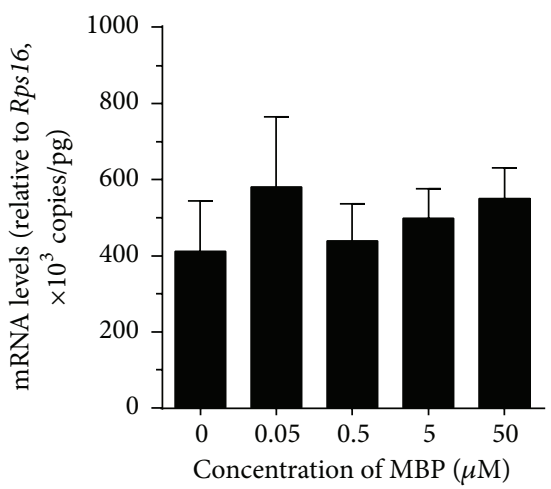

(f) Cyp17al

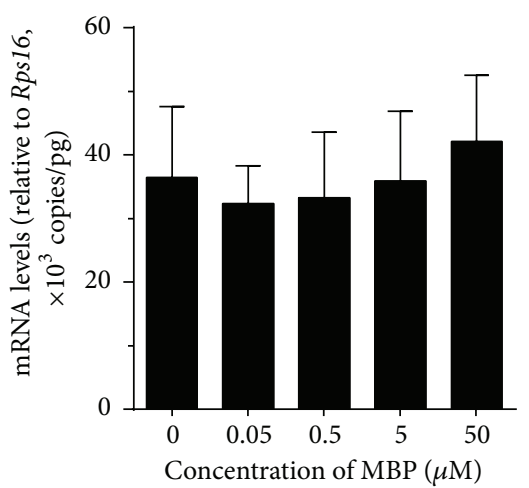

(i) AKR1C14

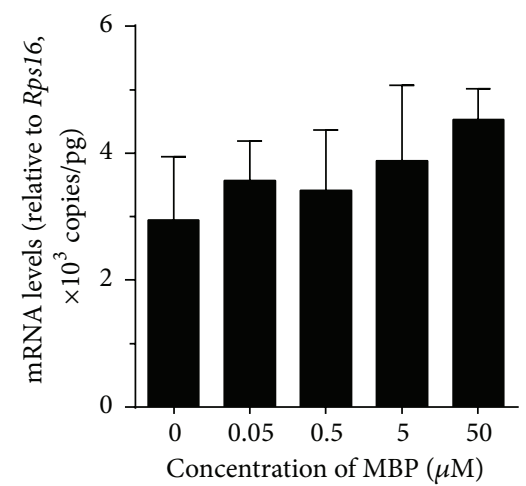

(l) Condl

FIGURE 6: Effects of MBP on the expression levels of steroidogenesis related genes in rat immature Leydig cells. Rat immature Leydig cells were cultured with $0.05-50 \mu \mathrm{M} \mathrm{MBP}$ for $3 \mathrm{hrs}$. The expression levels of steroidogenesis related genes were measured and calculated relatively to Rps16, the internal control. Mean $\pm \mathrm{SEM}, n=4 ; *, * *$, and $* * *$ indicate significant difference when compared to control at $P<0.05$, 0.01 , and 0.001 , respectively. 


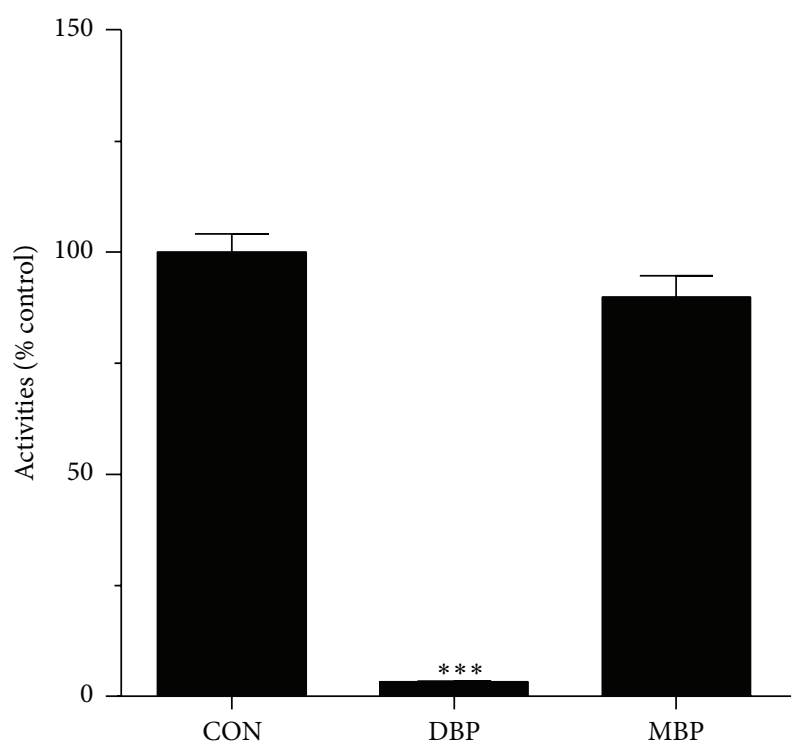

(a) CYP11A1

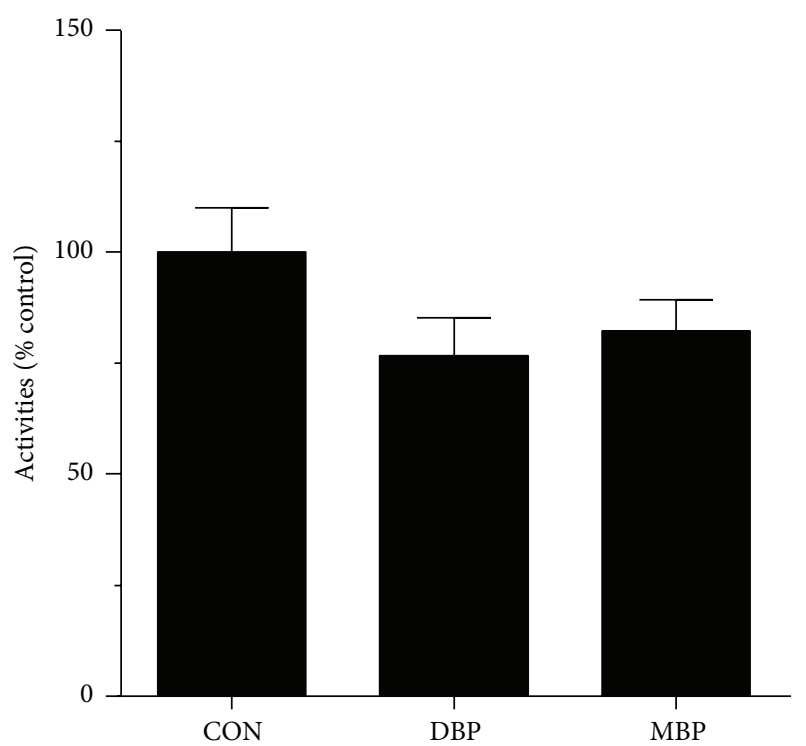

(c) SRD5A1

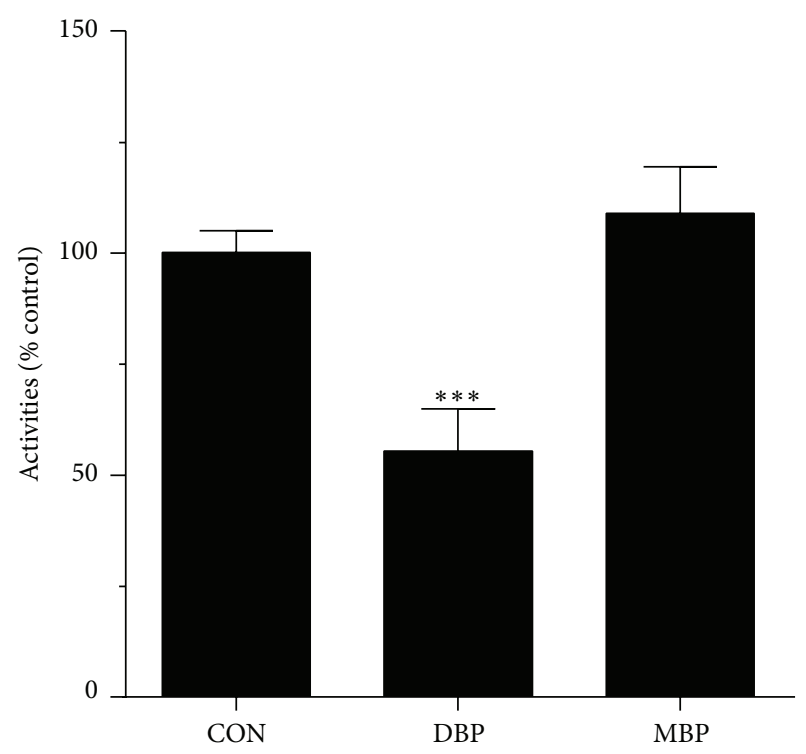

(b) CYP17Al

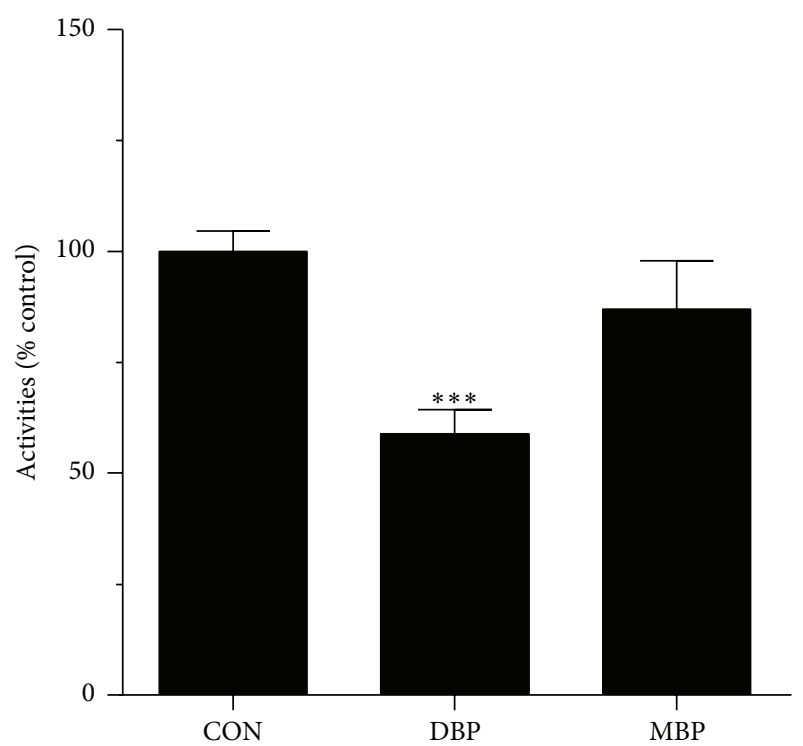

(d) AKR1C14

FIGURE 7: Direct effects of DBP and MBP on androgen biosynthetic and metabolizing enzyme activities in rat testes. Rat testis enzymes were measured with $50 \mu \mathrm{M}$ DBP and MBP. The $\%$ activity of control was calculated. Mean \pm SEM, $n=4 ; *, * *$, and $* * *$ indicate significant difference when compared to control at $P<0.05,0.01$, and 0.001 , respectively.

Inhibitions in these key biosynthetic enzymes surely could contribute to the inhibition of testosterone production by DBP and MBP, but the diversity of enzyme and gene expression inhibition ability indicate different mechanism of inhibition between DBP and MBP. Apparently, the inhibitions in synthetic pathway may play more dominant role than that in the metabolic process because, even in the face of reductions in metabolic process, testosterone was still reduced.

Our previous study demonstrated that rat immature Leydig cells showed some mitosis ability [22]. In the present study, we found that DBP but not MBP promoted Pcna expression. PCNA (proliferating cell nuclear antigen) is a biomarker of Leydig cell proliferation [23-25]. Increased Pcna expression levels indicate that DBP induces the proliferation of rat immature Leydig cells. Indeed, it was reported that Pcna expression levels were also higher in the Leydig cells after in utero DBP exposure [26].

MBP is the main metabolite of DBP after oral administration [27]. It has been reported that MBP was the major metabolite in the urine of the children (8 years old) [28], juveniles (12 years old) [29], and adults (32 years old in average) [30]. Due to the wide use as a material for cosmetics, the endocrine disruption of DBP has caused public concern. 
Indeed, it has been reported that the urinary phthalate metabolite levels were negatively related to the reduced Leydig cell function and poor quality of semen $[3,4]$.

In conclusion, DBP and its metabolite MBP showed different potencies to inhibit androgen production in rat immature Leydig cells. MBP was about 1000-fold more potent than its parent compound DBP. At lower concentrations, MBP inhibited androgen production mostly via the downregulation of Cyp11a1 and $H s d 3 b 1$ expression levels. At the higher concentration $(50 \mu \mathrm{M})$, DBP inhibited androgen production mostly via direct inhibition of CYP11A1, HSD3B1, and HSD17B3 activities or downregulating Star and Hsd3b1 expression levels.

\section{Competing Interests}

Authors declare no conflict of interests that would prejudice the paper impartiality.

\section{Acknowledgments}

This work was partially supported by the Wenzhou Science \& Technology Bureau (Y2014657), the Health and Family Planning Commission of Zhejiang Province (2013ZDA017, 2014KYA263, 2015103197, 2015KYA237, 2016KYB202, and 2016KYB199), and the Zhejiang Provincial Natural Science Foundation of China (LQ16H040004, LQ16H040005), Science Technology Department of Zhejiang province (2012C13016-1), and NSFC (81373032).

\section{References}

[1] B. C. Blount, M. J. Silva, S. P. Caudill et al., "Levels of seven urinary phthalate metabolites in a human reference population," Environmental Health Perspectives, vol. 108, no. 10, pp. 979-982, 2000.

[2] M. C. Kohn, F. Parham, S. A. Masten et al., "Human exposure estimates for phthalates," Environmental Health Perspectives, vol. 108, no. 10, pp. A440-A442, 2000.

[3] W.-H. Chang, S.-S. Li, M.-H. Wu, H.-A. Pan, and C.-C. Lee, "Phthalates might interfere with testicular function by reducing testosterone and insulin-like factor 3 levels," Human Reproduction, vol. 30, no. 11, pp. 2658-2670, 2015.

[4] M. S. Bloom, B. W. Whitcomb, Z. Chen, A. Ye, K. Kannan, and G. M. Buck Louis, "Associations between urinary phthalate concentrations and semen quality parameters in a general population," Human Reproduction, vol. 30, no. 11, pp. 26452657, 2015.

[5] G.-X. Hu, Q.-Q. Lian, R.-S. Ge, D. O. Hardy, and X.-K. Li, "Phthalate-induced testicular dysgenesis syndrome: leydig cell influence," Trends in Endocrinology and Metabolism, vol. 20, no. 3, pp. 139-145, 2009.

[6] S. van den Driesche, C. McKinnell, A. Calarrão et al., "Comparative effects of di(n-butyl) phthalate exposure on fetal germ cell development in the rat and in human fetal testis xenografts," Environmental Health Perspectives, vol. 123, no. 3, pp. 223-230, 2015.

[7] J. R. Rodriguez-Sosa, A. Bondareva, L. Tang et al., "Phthalate esters affect maturation and function of primate testis tissue ectopically grafted in mice," Molecular and Cellular Endocrinology, vol. 398, no. 1-2, pp. 89-100, 2014.

[8] U. M. Bello, M. C. Madekurozwa, H. B. Groenewald, T. A. Aire, and A. Arukwe, "The effects on steroidogenesis and histopathology of adult male Japanese quails (Coturnix coturnix japonica) testis following pre-pubertal exposure to di(n-butyl) phthalate (DBP)," Comparative Biochemistry and Physiology Part C: Toxicology \& Pharmacology, vol. 166, pp. 24-33, 2014.

[9] X. Chen, Q.-H. Zhou, L. Leng, X. Chen, Z.-R. Sun, and N.J. Tang, "Effects of di(n-butyl) and monobutyl phthalate on steroidogenesis pathways in the murine Leydig tumor cell line MLTC-1," Environmental Toxicology and Pharmacology, vol. 36, no. 2, pp. 332-338, 2013.

[10] E. Mylchreest, M. Sar, D. G. Wallace, and P. M. Foster, "Fetal testosterone insufficiency and abnormal proliferation of Leydig cells and gonocytes in rats exposed to di(n-butyl) phthalate," Reproductive Toxicology, vol. 16, no. 1, pp. 19-28, 2002.

[11] R.-S. Ge, G.-R. Chen, C. Tanrikut, and M. P. Hardy, "Phthalate ester toxicity in Leydig cells: developmental timing and dosage considerations," Reproductive Toxicology, vol. 23, no. 3, pp. 366373, 2007.

[12] H. Chen, R.-S. Ge, and B. R. Zirkin, "Leydig cells: from stem cells to aging," Molecular and Cellular Endocrinology, vol. 306, no. 1-2, pp. 9-16, 2009.

[13] R.-S. Ge, Q. Dong, C. M. Sottas, V. Papadopoulos, B. R. Zirkin, and M. P. Hardy, "In search of rat stem Leydig cells: identification, isolation, and lineage-specific development," Proceedings of the National Academy of Sciences of the United States of America, vol. 103, no. 8, pp. 2719-2724, 2006.

[14] R.-S. Ge and M. P. Hardy, "Variation in the end products of androgen biosynthesis and metabolism during postnatal differentiation of rat leydig cells," Endocrinology, vol. 139, no. 9, pp. 3787-3795, 1998.

[15] R. S. Ge and M. P. Hardy, "Regulation of Leydig cells during pubertal development," in The Leydig Cell in Health and Disease, A. H. Payne and M. P. Hardy, Eds., pp. 55-70, Humana Press, Totowa, NJ, USA, 2007.

[16] A. H. Payne, K. L. Wong, and M. M. Vega, "Differential effects of single and repeated administrations of gonadotropins on luteinizing hormone receptors and testosterone synthesis in two populations of Leydig cells," The Journal of Biological Chemistry, vol. 255, no. 15, pp. 7118-7122, 1980.

[17] R.-S. Ge, H.-B. Gao, V. L. Nacharaju, G. L. Gunsalus, and M. P. Hardy, "Identification of a kinetically distinct activity of 1lbeta-hydroxysteroid dehydrogenase in rat leydig cells," Endocrinology, vol. 138, no. 6, pp. 2435-2442, 1997.

[18] G.-X. Hu, H.-Y. Zhou, X.-W. Li et al., "The (+)- and (-)gossypols potently inhibit both $3 \beta$-hydroxysteroid dehydrogenase and $17 \beta$-hydroxysteroid dehydrogenase 3 in human and rat testes," Journal of Steroid Biochemistry and Molecular Biology, vol. 115, no. 1-2, pp. 14-19, 2009.

[19] J. Guo, H. Zhou, Z. Su et al., "Comparison of cell types in the rat Leydig cell lineage after ethane dimethanesulfonate treatment," Reproduction, vol. 145, no. 4, pp. 371-380, 2013.

[20] H. Lin, R.-S. Ge, G.-R. Chen et al., "Involvement of testicular growth factors in fetal Leydig cell aggregation after exposure to phthalate in utero," Proceedings of the National Academy of Sciences of the United States of America, vol. 105, no. 20, pp. 7218$7222,2008$.

[21] K. Yuan, B. Zhao, X.-W. Li et al., "Effects of phthalates on $3 \beta$-hydroxysteroid dehydrogenase and $17 \beta$-hydroxysteroid 
dehydrogenase 3 activities in human and rat testes," ChemicoBiological Interactions, vol. 195, no. 3, pp. 180-188, 2012.

[22] R. S. Ge and M. P. Hardy, "Decreased cyclin A2 and increased cyclin G1 levels coincide with loss of proliferative capacity in rat Leydig cells during pubertal development," Endocrinology, vol. 138, no. 9, pp. 3719-3726, 1997.

[23] J. Borch, M. Dalgaard, and O. Ladefoged, "Early testicular effects in rats perinatally exposed to DEHP in combination with DEHA - apoptosis assessment and immunohistochemical studies," Reproductive Toxicology, vol. 19, no. 4, pp. 517-525, 2005.

[24] C. R. González, B. González, M. E. Matzkin et al., "Psychostimulant-induced testicular toxicity in mice: evidence of cocaine and caffeine effects on the local dopaminergic system," PLoS ONE, vol. 10, no. 11, Article ID e0142713, 2015.

[25] K. Svechnikov, I. Savchuk, M. L. Morvan, J. P. Antignac, B. Le Bizec, and O. Soder, "Phthalates exert multiple effects on leydig cell steroidogenesis," Hormone Research in Paediatrics, 2015.

[26] K. M. Sargent, R. M. McFee, R. S. Gomes, and A. S. Cupp, "Vascular endothelial growth factor A: just one of multiple mechanisms for sex-specific vascular development within the testis?" Journal of Endocrinology, vol. 227, no. 2, pp. R31-R50, 2015.

[27] P. W. Albro and B. Moore, "Identification of the metabolites of simple phthalate diesters in rat urine," Journal of Chromatography, vol. 94, pp. 209-218, 1974.

[28] Y.-J. Lien, H.-Y. Ku, P.-H. Su et al., "Prenatal exposure to phthalate esters and behavioral syndromes in children at 8 years of age: Taiwan maternal and infant cohort study," Environmental Health Perspectives, vol. 123, no. 1, pp. 95-100, 2015.

[29] Q. Shen, H. Shi, Y. Zhang, and Y. Cao, "Dietary intake and phthalates body burden in boys and girls," Archives of Public Health, vol. 73, no. 1, article 5, 2015.

[30] X. Han, Z. Cui, N. Zhou et al., "Urinary phthalate metabolites and male reproductive function parameters in Chongqing general population, China," International Journal of Hygiene and Environmental Health, vol. 217, no. 2-3, pp. 271-278, 2014. 

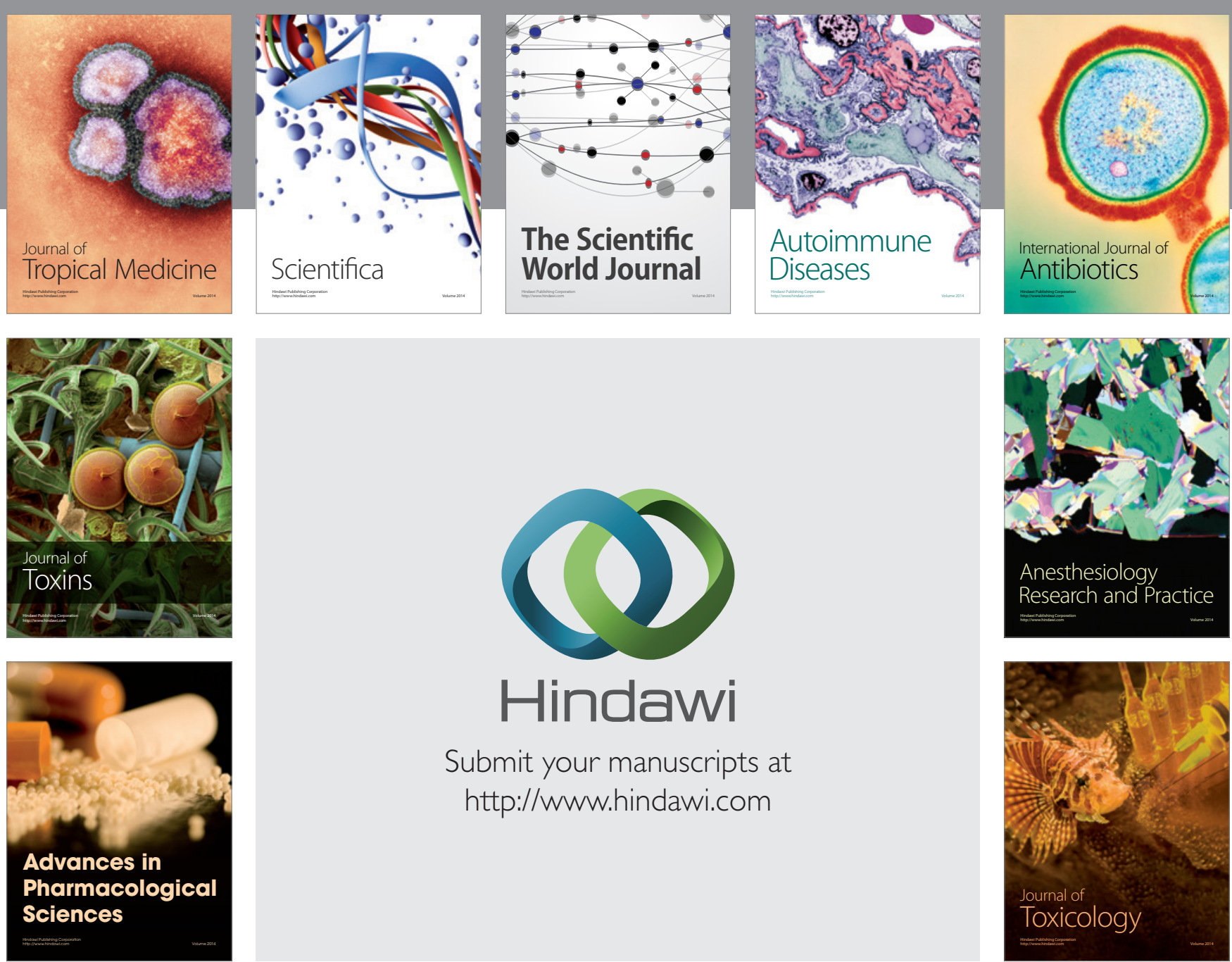

\section{Hindawi}

Submit your manuscripts at

http://www.hindawi.com
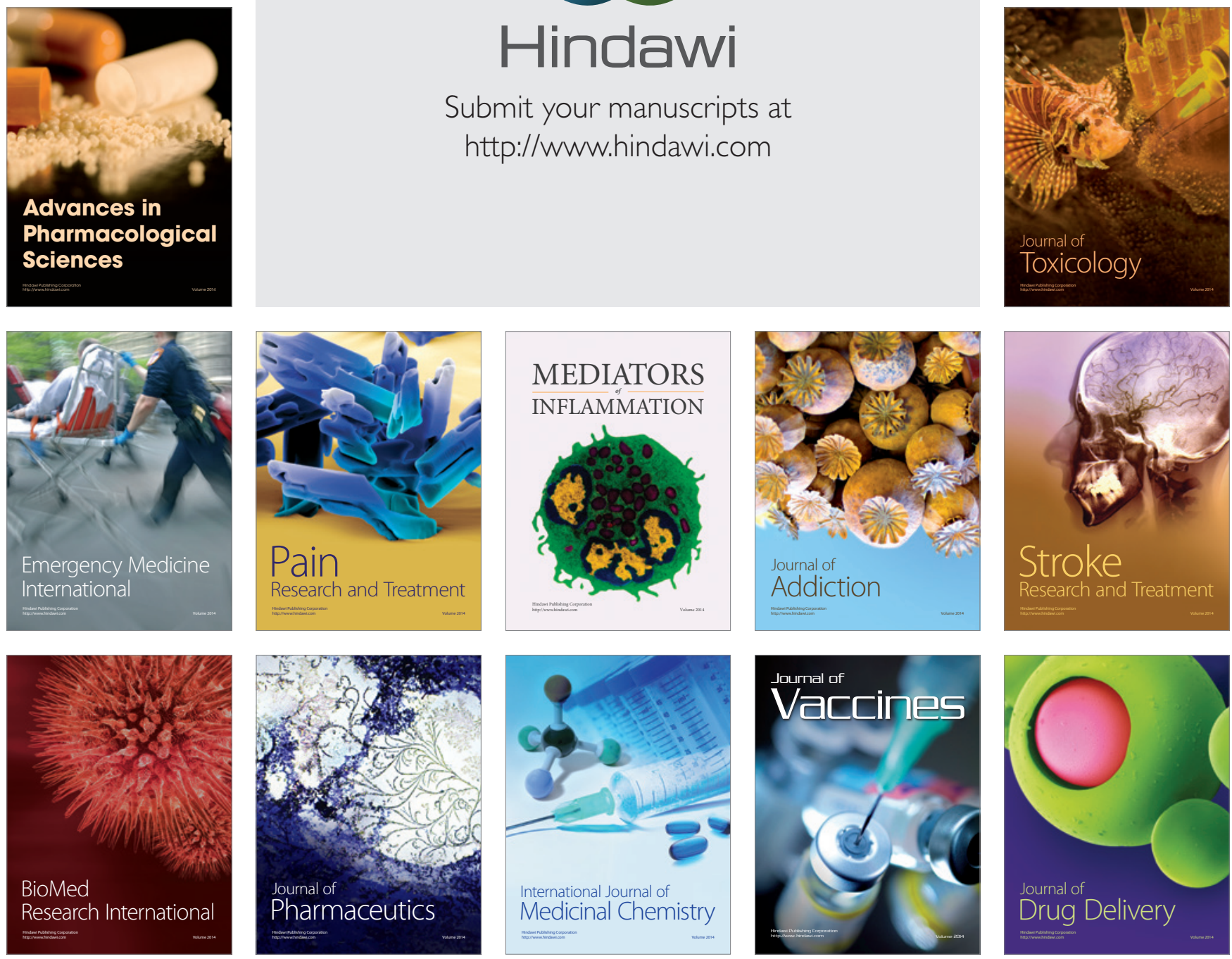